\title{
IMPROVING CHANNEL FLOW WITH DEFLECTORS Optimized Using a Genetic Algorithm
}

\author{
FUCAK, S.; CARIJA, Z. \& MRSA, Z.
}

Abstract: This paper summarizes the optimization process for deflectors designed to lower the water level and ceiling overflow in the S-shaped outflow channel of HPP Vinodol. Parameterized designs of deflectors were optimized using a genetic algorithm that evaluated each setup by running $2 D$ CFD simulations. Optimal designs were chosen by considering total pressure loss and flow uniformity. The resulting best case design set provided a solid basis for simulations using $3 D$ fluid flow numerical models of the channel. Two variants of $3 D$ deflector designs were simulated and a two phase VoF model was used to simulate the free surface with and without deflectors. Both $2 D$ and $3 D$ simulation results show improvements in channel flow and a significantly lower water level justifies further development of deflector design for $3 D$ optimization and a future prototype test.

Key words: genetic algorithm, channel flow, deflector, shape optimization, CFD
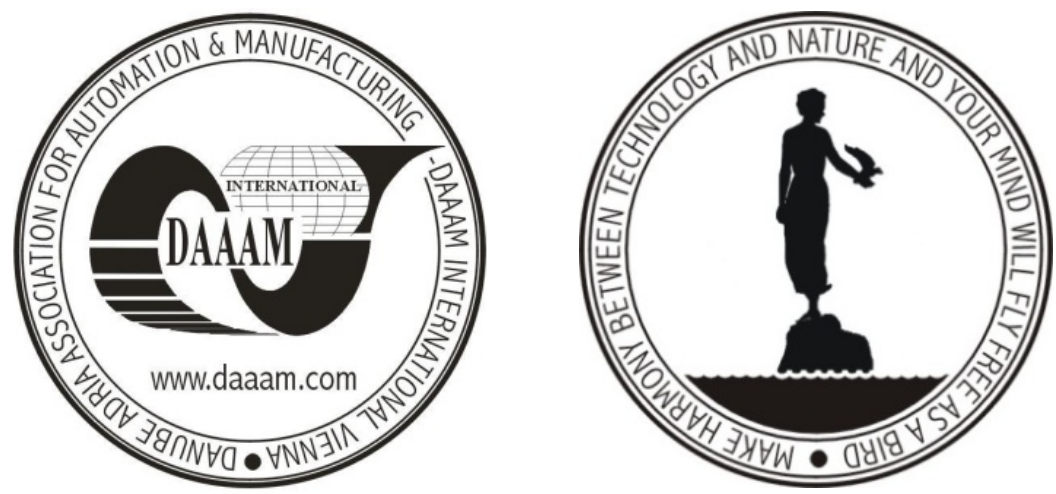

Authors' data: Dipl. Ing. Fucak, S[anjin]; Doc. Dr. Sc. Carija, Z[oran]; Univ. Prof. Dr. Sc. Mrsa, Z[oran], Faculty of Engineering, University of Rijeka, Vukovarska 58, 51000 Rijeka, Croatia, sanjinf@riteh.hr, zcarija@riteh.hr,mrsa@riteh.hr

This Publication has to be referred as: Fucak, S[anjin]; Carija, Z[oran] \& Mrsa, Z[oran] (2009). Improving Channel Flow with Deflectors Optimized Using a Genetic Algorithm, Chapter 70 in DAAAM International Scientific Book 2009, pp. 721-734, B. Katalinic (Ed.), Published by DAAAM International, ISBN 978-3-901509-69-8, ISSN 1726-9687, Vienna, Austria

DOI: $10.2507 /$ daaam.scibook.2009.70 